\title{
مقاله مروى
}

\section{كنترل تشنج هاى صرعى با استفاده از تحريكات الكتريكى عمقى مغز با فر كانس كم: مرورى بر مكانيسمهاى احتمالى}

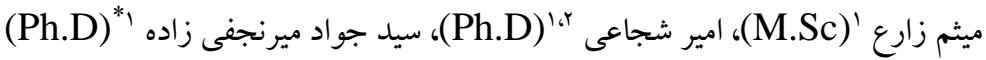

$$
\begin{aligned}
& 1 \text { - كروه فيزيولوزي، دانشكده علوم يزنشكى، دانشكاه تربيت مدرس، تهران، ايران }
\end{aligned}
$$

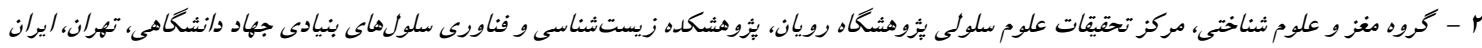

\section{$0 \mathrm{Pu}$}

صرع يكى از شايع ترين بيمارىهاى عصبى است كه هنوز روش قطعى براى درمان آن شناخته نشده است. راه اصلى درمان و و وران

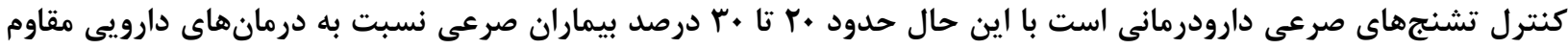

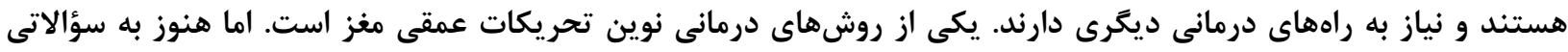

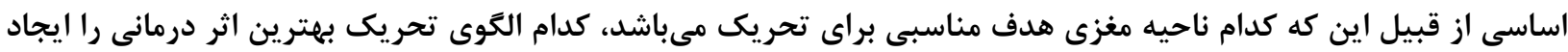

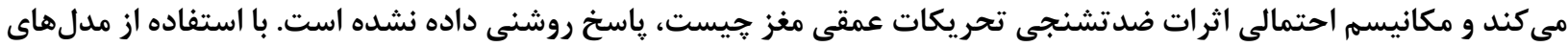
آزمايشعاهى صرع و تشنج نشان داده شده است كه تحريكات الكتريكى با فركانس كم كم

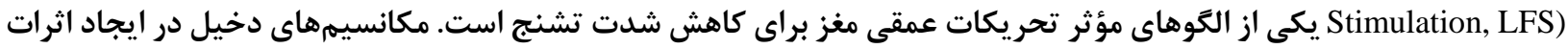

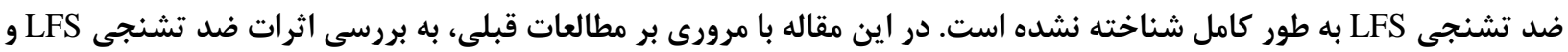

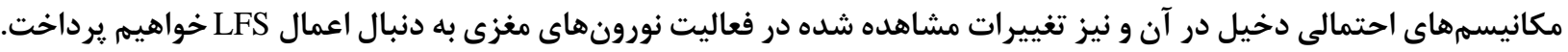

$$
\text { وازههاى كليدى: صرع؛ تحريك عمقى مغز؛ تحريك الكتريكى با فر كانس كم؛ اثر ضد تشنجى }
$$

ز بيمارى صرع، بايد روشهاى درمانى ديخرى را براى اين بيماران جستجو كرد. روش ديخرى كه به عنوان درمان بالقوه در بـ بردي بيماران صرعى مقاوم به دارويى كه كانديداى جراحى نيز نمىباشند مطرح شده است، به كار بردن تحريك عمقى مغز

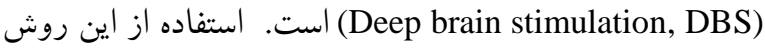
در صرعهاى مقاوم به دارو نتايج مطلوبى از خود نشان داده است

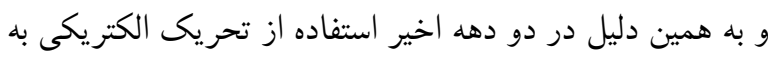
عنوان درمان كمكى و كاه به عنوان درمان اصلى در بيماران صرعى مقاوم به درمان مورد توجه قرار گرفتنه است. تحريكات الكتريكى عمقى مغز

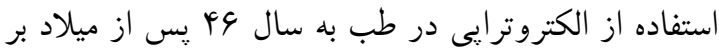

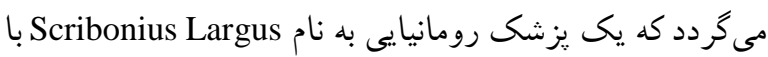
استفاده از يك گونه ماهى به نام ماهى سياه Torpedo (كه قادر به توليد الكتر يسيته بود) درد را در بيماران مبتلا به سردرد تسكين

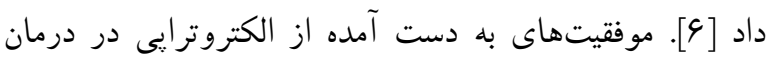

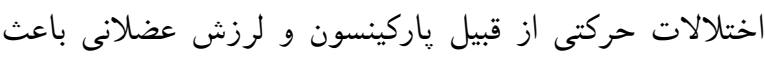
تشويق دانشمندان در استفاده از آن در بيماران صرع شد. درمان

\section{مقدمه}

صرع يكى از اختلالات عصبى شايع در جهان است به طورى

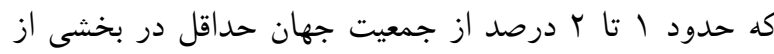
زندگى خود با اين مشكل مواجه هستند [ (Y،]. رايجترين روش درمانى براى مقابله با صرع، روش دارو درمانى است؛ هر ¥ند داروهاى ضد-صرعى عوارض جانبى نسبتاً زيادى نيز دارند. داروهاى ضد صرع موجود در • F درصد موارد تثنج را از بين مىبرند و در بقيه موارد فقط فراوانى وقوع تشنجها راكم مى مكند

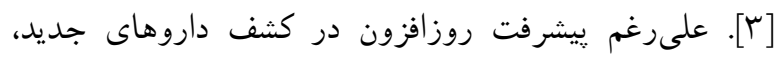

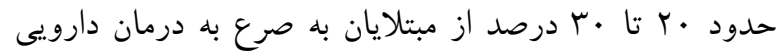

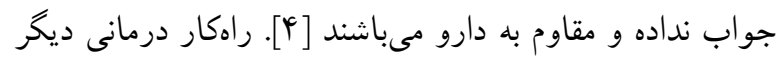

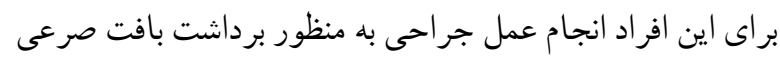
و يا قطع كردن ارتباطات كانون تشنج با ساير نواحى مغزى است.

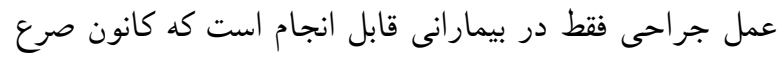

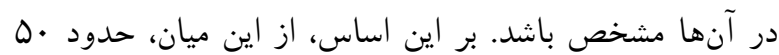
درصد افراد به دلايلى، مثل جند كانونى بودن تشنج، قادر به انجام إنيا

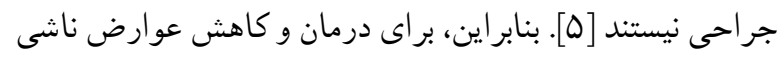


مؤثرند و ب) تحريك مستقيم كانون صرعى. تحريكات عمقى

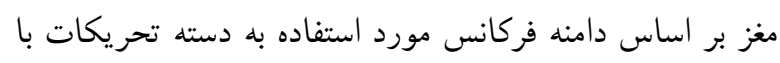

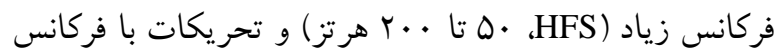

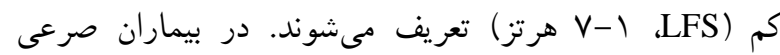

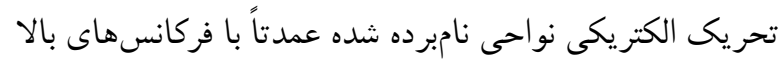

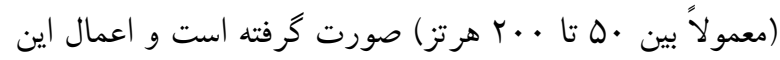

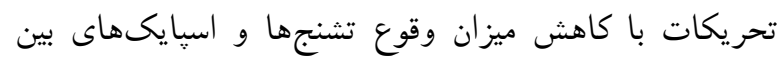

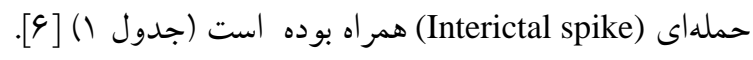
با وجود اثرات مطلوب و ضدتشنجى ناشى از كاربرد

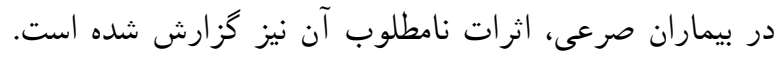

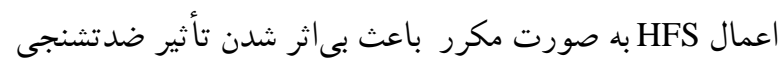

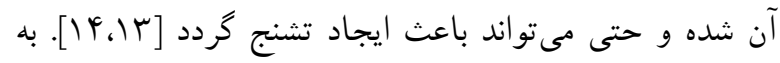

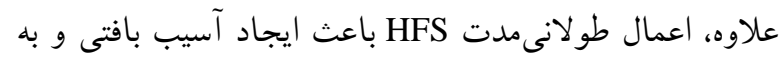

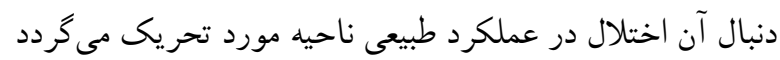

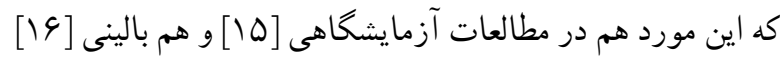
كزارش شده است. بسيارى از تحقيقات نشان دادهاند كه اعمال

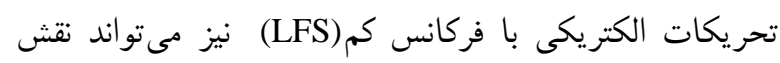

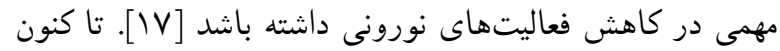

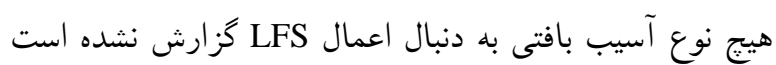

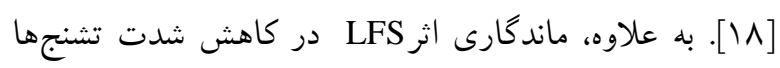
بسيار بيشتر از HFS مىباشد [19]
با تحريك الكتريكى به صورتهاى مختلفى مىتواند صورت

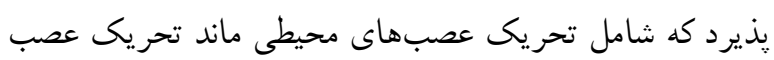

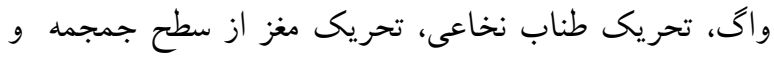

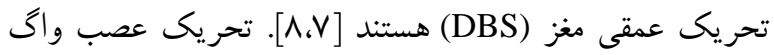

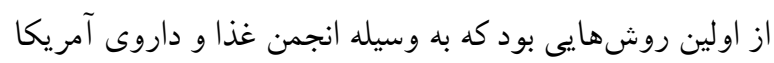

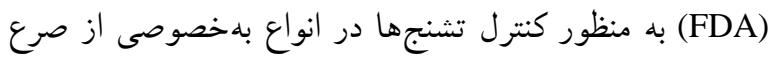

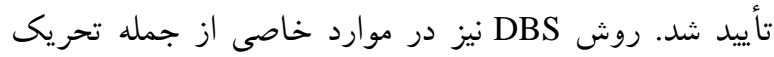

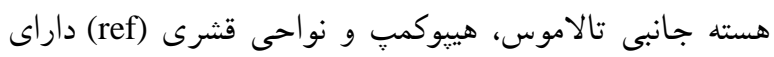

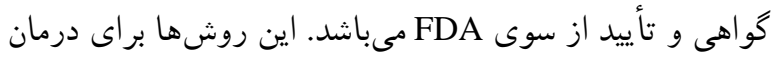

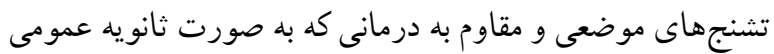

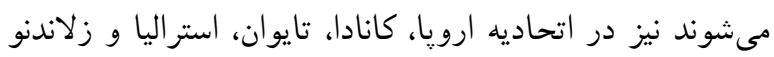
تأييديه دريافت كردهاند.

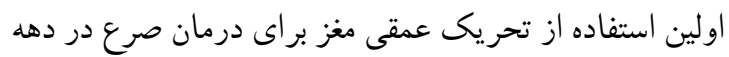

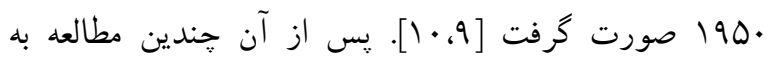
صورت موردى اثرات ضدتشنجى تحريك عمقى مغز ران انشان

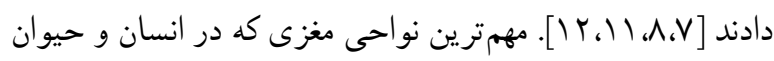

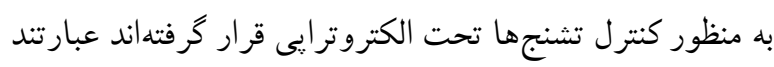

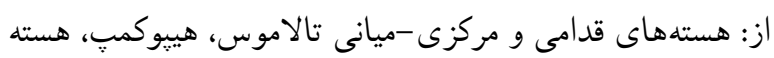
دمدار، ماده سياه، هسته لوكوس سرولئوس، مخجه،، هسته هاى

تحت تالاموسى و كانونهاى صرعى قشر مغز [†] به طور كلى استفاده از تحريك الكتر يكى عمقى براى كنى كنترل

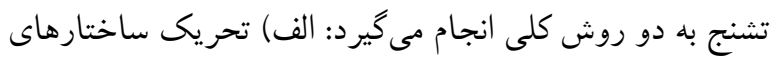

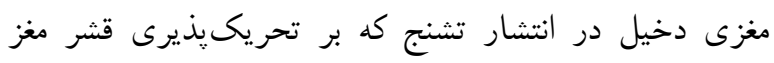

جدول ا. خلاصه اى از نتايج مطالعات قبلى براى بررسى تأثير اعمال تحريك عمقى مغز در بيماران صرعى. مواردى كه با خط تيره نشان داده شده در مقاله مسكوت مانده و به آن اشاره نشده است مغن در بيماران.

\begin{tabular}{|c|c|c|c|c|c|c|}
\hline \multirow[b]{2}{*}{ 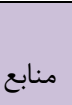 } & \multirow{2}{*}{ درصد كاهش } & \multirow{2}{*}{ نوع تشنج } & \multicolumn{3}{|c|}{ كميت هاى تحريك عمقى مغز } & \multirow{2}{*}{ تاحيه اعمال } \\
\hline & & & عرض پالس (بs) & ولتاز (V) & فر كانس (Hz) & \\
\hline [६६] & $\% . \Delta 9$ & تشنج تونيك - كلونيك & 9 . & $\Delta$ & IfD & \multirow{3}{*}{ 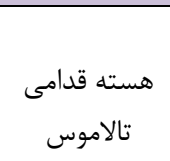 } \\
\hline$[q V]$ & $\%$. & تشنج تونيك - كلونيك، تشنج ساده & 9 . & $r / \Delta-r^{r}$ & $f-\Lambda$ & \\
\hline$[\varepsilon \wedge]$ & $\% .9$. & تشنج ساده & - & - & - & \\
\hline [६9] & \% & - & 9 . & - & $1 \wedge \Delta$ & \multirow{3}{*}{ هييو كمب } \\
\hline$[\vee \cdot]$ & $\%$ & تشنج تونيك - كلونيك & 19 . & $. / D-14$ & $r \cdot$. & \\
\hline 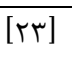 & $\%$ FQ & تشنج تونيك - كلونيك & 9 . & 1 & IF & \\
\hline [vi] & $\%$. & تشنج تونيك - كلونيك، صرع غايب،تشنج & r.. & r & 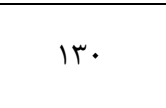 & \multirow{3}{*}{ هسته مركزى - هيانى تالاموس } \\
\hline$[V Y]$ & $\%$. & صرع غايب & 9 . & $\geq 0$ & q. & \\
\hline$[\xi \wedge]$ & - & تشنج ميوكولونيك & - & - & - & \\
\hline$[V \pi]$ & $\% \uparrow \wedge$ & - & 9 . & $\Delta$ & ITS & هسته اكومبنس \\
\hline$[V q]$ & $\% q \Delta$ & تشنج تونيك- كلونيك & $r \cdot \cdot$ & $r-f$ & $\Delta \cdot-1 \cdots$ & \multirow{2}{*}{ مخجه } \\
\hline$[\vee v a]$ & $\% .9 \mathrm{~V}$ & تشنج تونيك-كلونيك، صرع غايب & $F \Delta$ & $r, Y \wedge$ & 1 . & \\
\hline
\end{tabular}


مىشود و هم فعاليت سينايسى را دستخوش تغيير كند و علاوه بر اين در سطح مولكولى نيز تغييراتى را ايجاد مىنمايد. الف) اثر LFS بر تقويت سينابسى: قدرت انتقال سينابسى

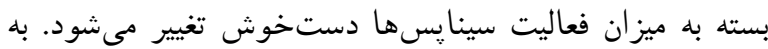

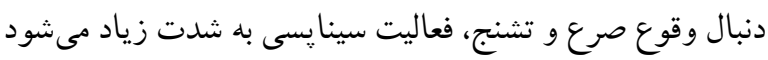

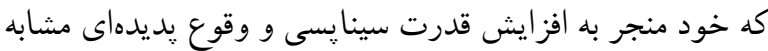

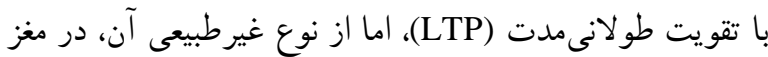

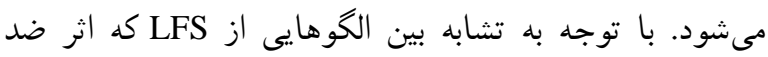

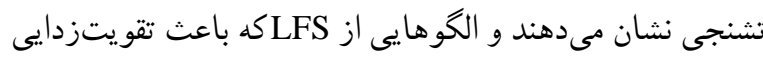
(Depotetation)

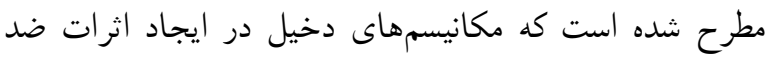

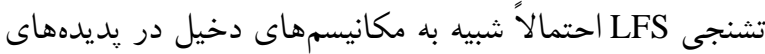
تقويتزدايى و يا LTD مىباشند. در همين راستا، در مطالعهاى

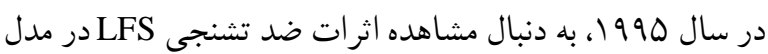

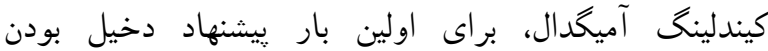
مكانيسمهايى مشابه با يديده تقويتزدايى و يا LTD براي الى توجيه

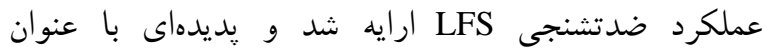

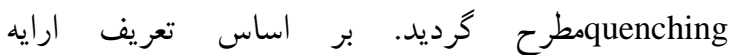
شده، quenching يك دستكارى فيز يولوزيكى است كه اثر قابل

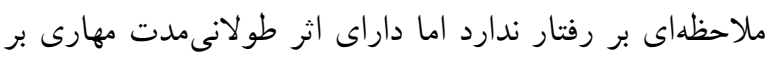

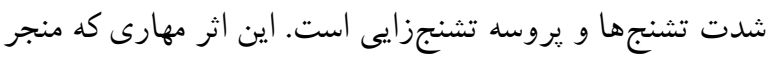

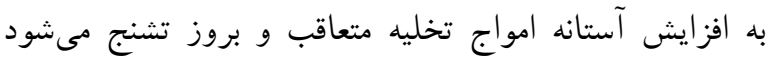

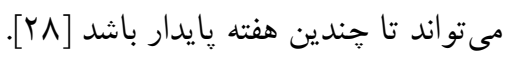

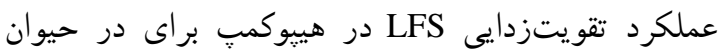

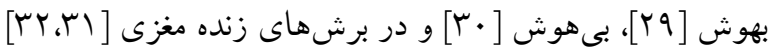

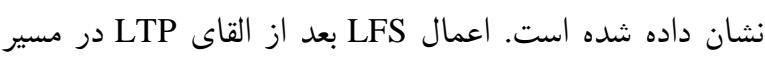
شاخههاى جانبى شافر به ناحيه CA1 باعث بركرداندن تقويت

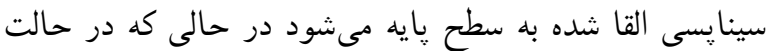

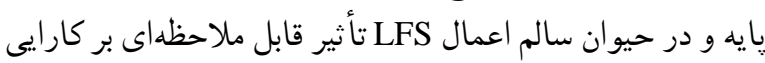
سينايسى ندارد. مشابه با اين مشاهدات، در سال 1999 در دالئ مطالعهاى كه در گربه بهوش انجام گرفت نشان داده شد كه اعمال Lاعث كاهش تقويت سينايسى ناشى از كيندلينگ آميكدال در سينإِهاى بين اين ناحيه با نواحى ميانى - شكمى آنسي هيبوتالاموس و ناحيه خاكسترى دور قنات مغزى مىشود [سبـ].

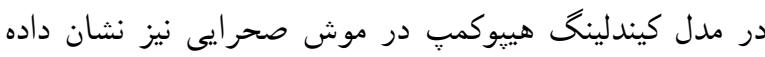

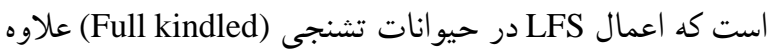
بر اثرات ضد تشنجى باعث كاهش تقويت سينايسى ناشى از

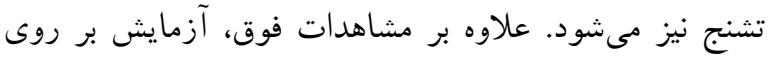

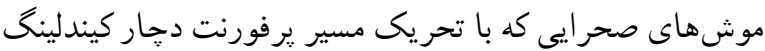

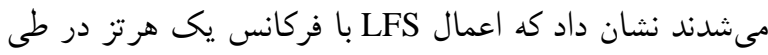

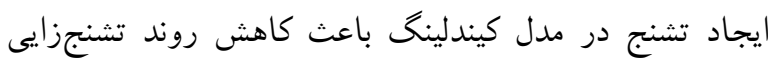

$$
\text { تحريك الكتريكى با فر كانس كم }
$$

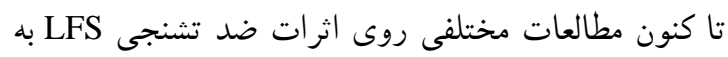

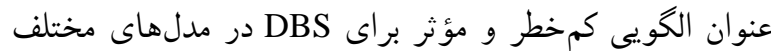

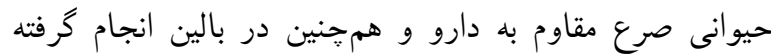

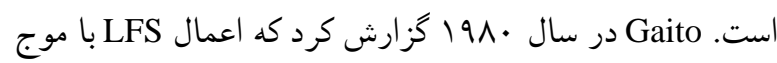

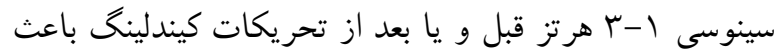
مهار قوى و پايدار فعاليت تشنجى در مدل كيندلينخ آميخدال

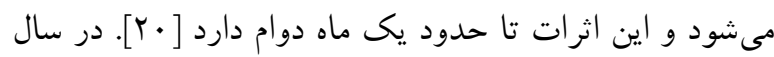

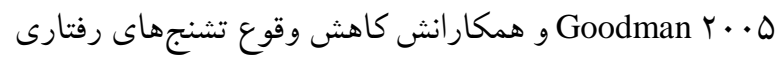

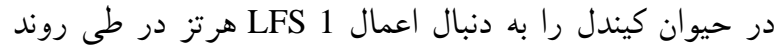

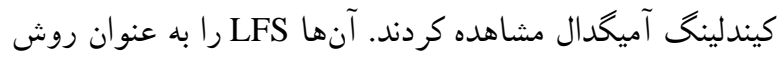

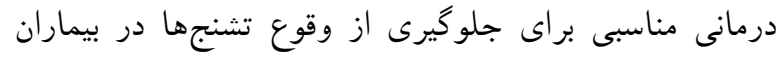

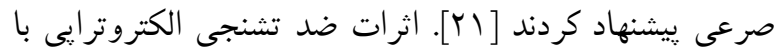

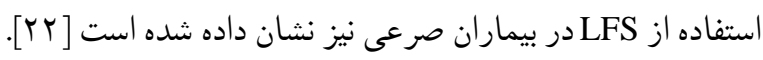

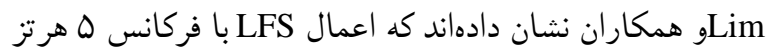
و عرض بالس •9 ميكرو ثانيه در ناحيه هيبوكمب باعث كاهش

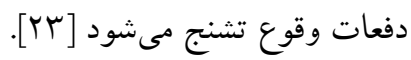

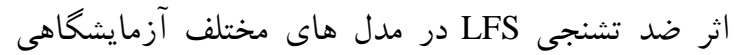
صرع و تشنج و در نواحى متفاوتى از مغز مشاهده شده است.

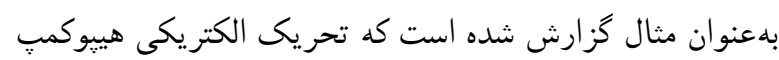

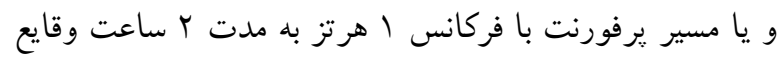
بين حملهاى را كاهش مىدهد ولى اثرى روى ميزان تشنجهاى بردي

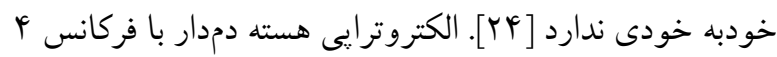
تا 4 هرتز موجب كاهش اسيايكهاى بين حملهاى و توقف

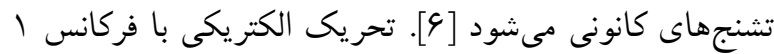

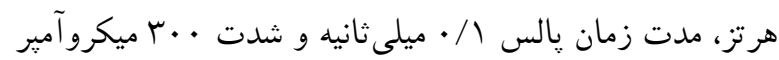
در سوبيكولوم موجب بروز اثرات بهبودى بخش درئ در مدل مدل ليتيوم

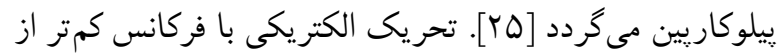
ه هرتز در شاخههاى جانبى شافر نيز باعث مهار فعاليتهاى

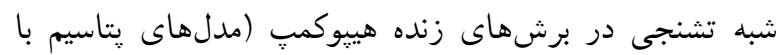
غلظت بالا و مدل فاقد منيزيم) مىشود [بك]. هم קنين اعمال

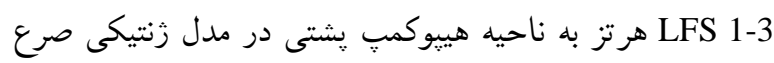

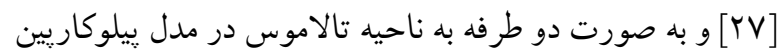

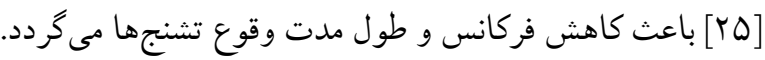

\section{مكانيسم عمل LFS}

شواهد زيادى مبنى بر مؤثر بودن اعمال LFS در كنترل

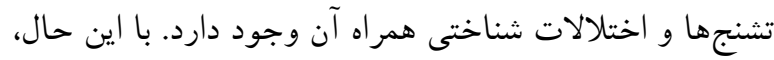

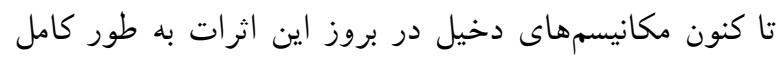

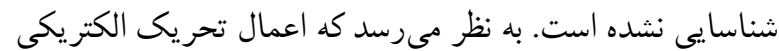
با فركانس كم هم باعث كاهش شليك اسبايك توسط نورونها 
داشت. علاوه بر اين، به دنبال اعمال LFS به ناحيه

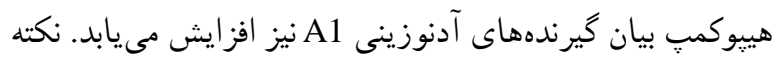

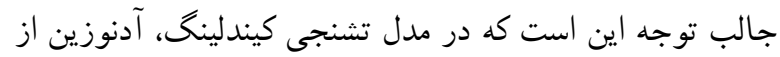

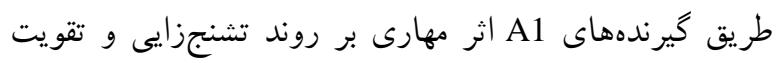

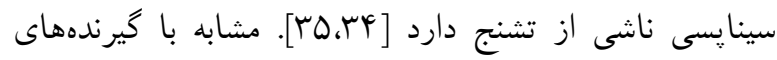

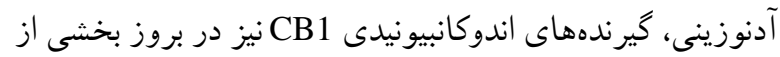

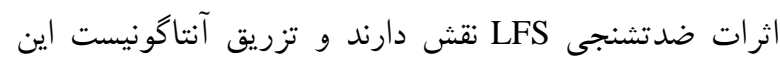

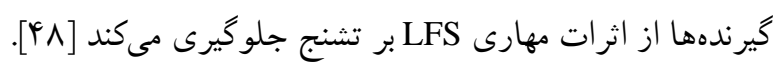
علاوه بر عوامل فوق در آزمايشى كه توسط صادق و همكاران

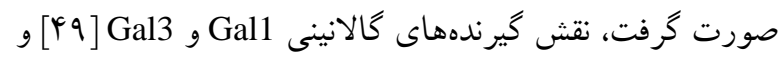

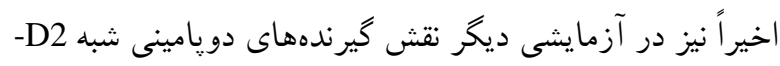
در بروز اثرات ضد تشنجى LFS به اثبات رسيده است.

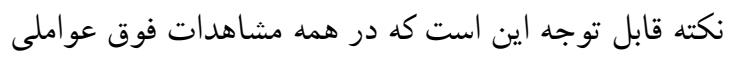

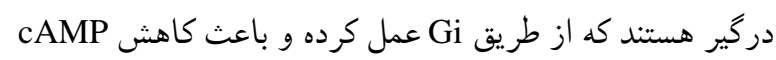

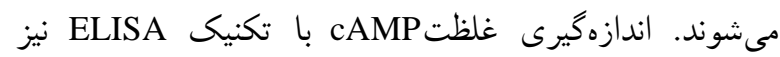
تاييدكننده اين فرضيه است و نشان داده شده است كه اعمال

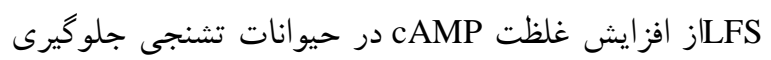

مىكند [Tr]

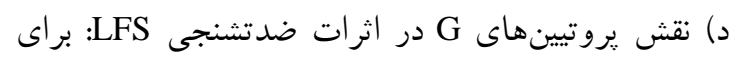

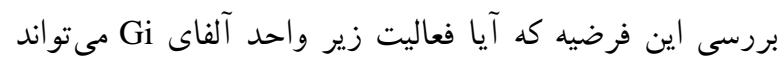

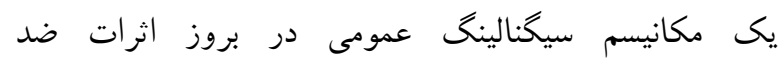

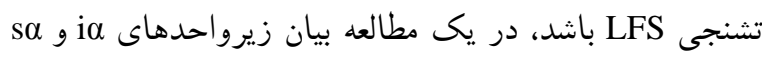

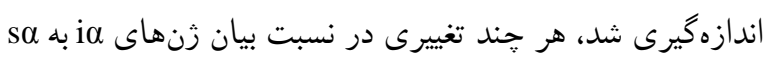

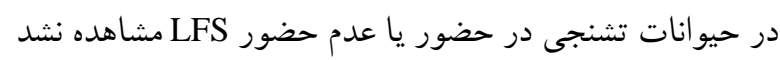

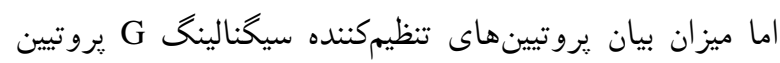

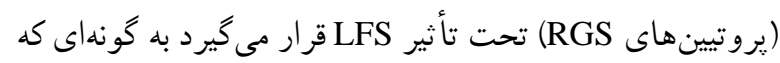

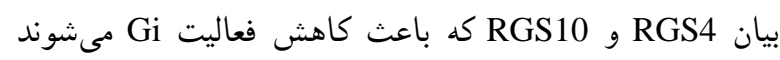

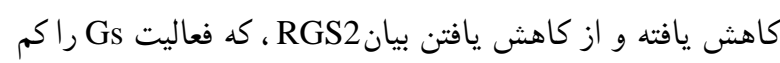

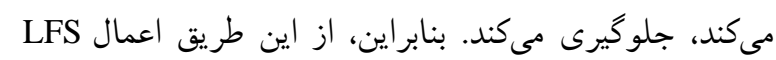

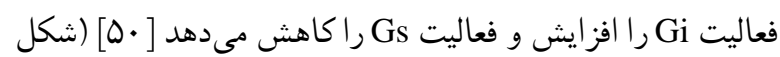

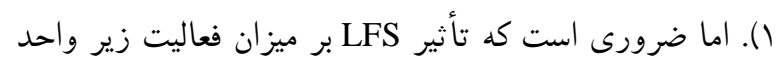

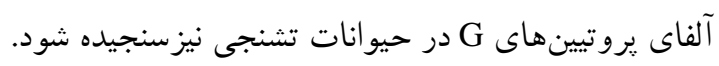

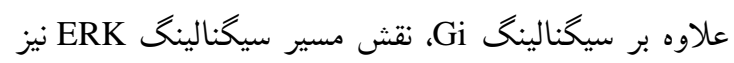

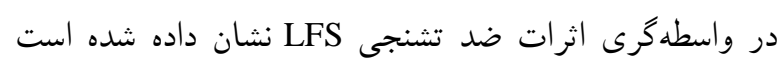

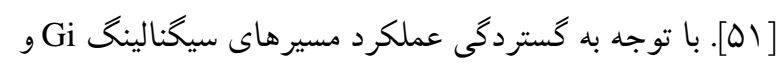

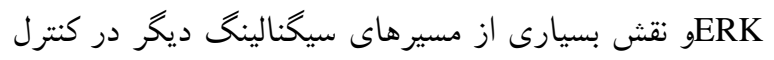

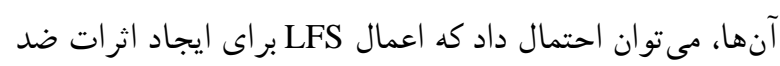

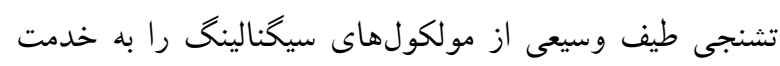

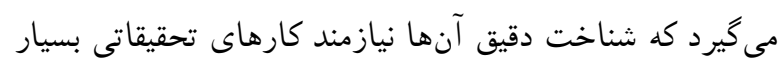
بيث ترى مىباشد.
مى شود و به موازات آن از افزايش تقويت سينإِى در طى روند

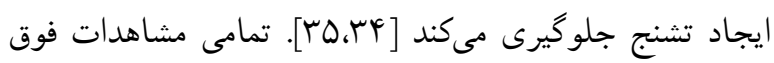

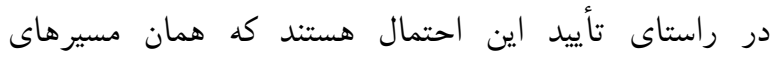

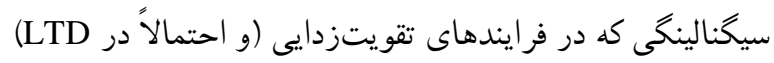

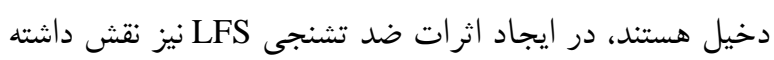

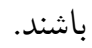

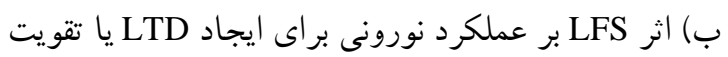

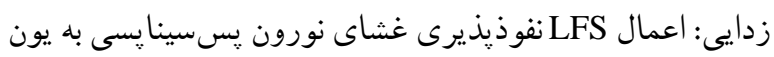

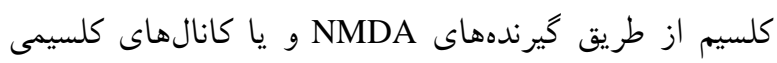

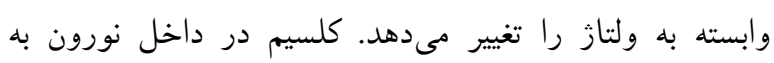

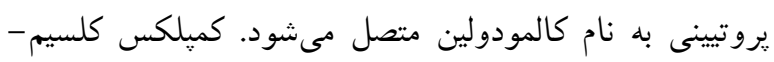

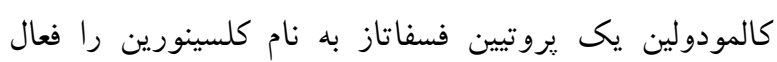

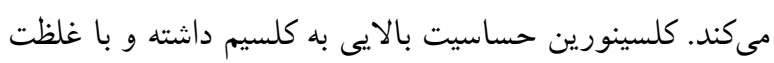

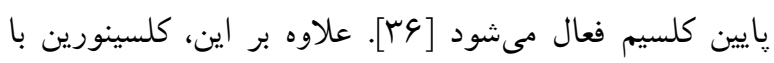

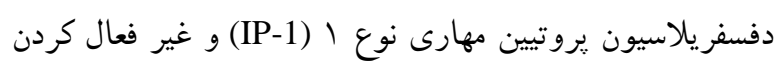

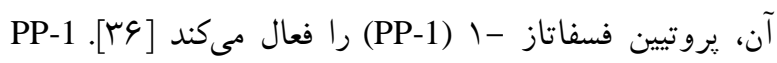

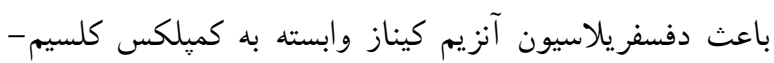

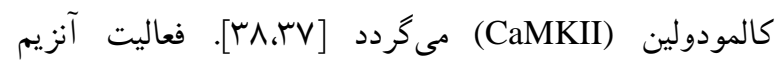

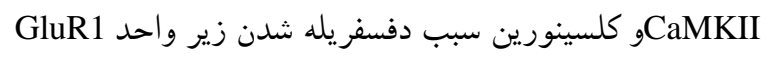

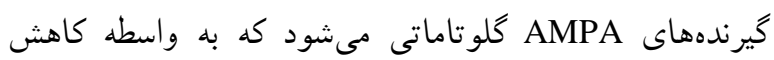

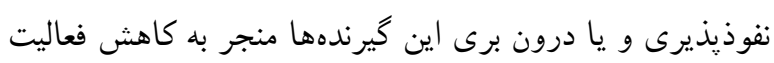

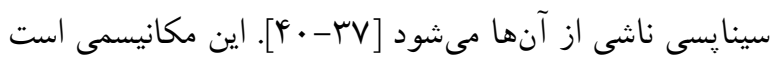

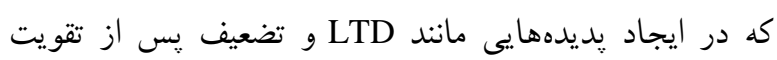

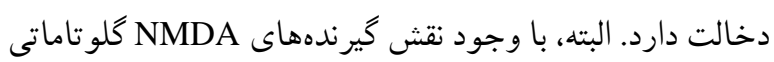

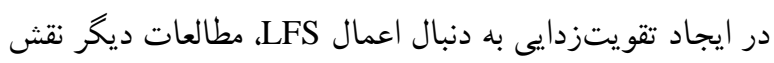

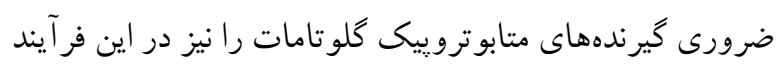

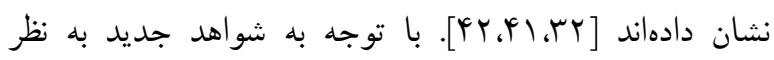

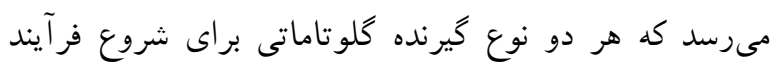

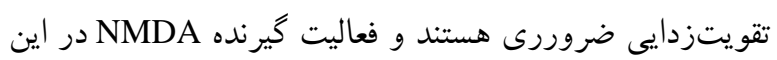

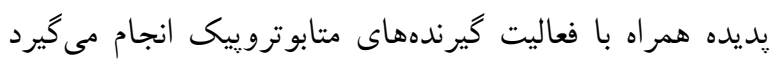

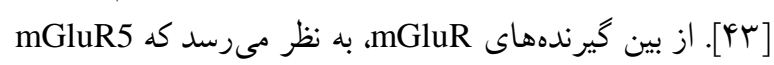

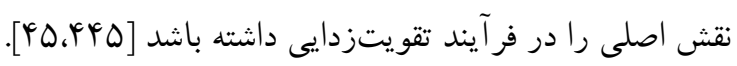

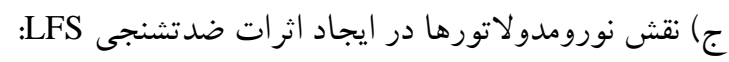

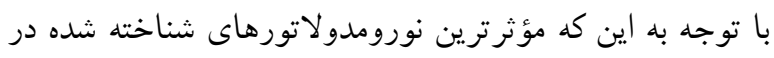

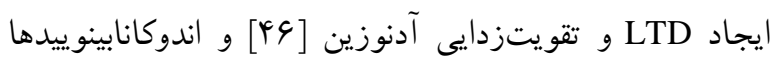

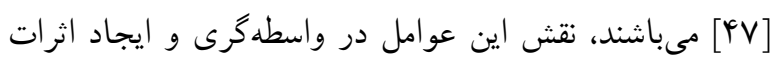

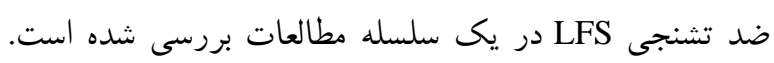

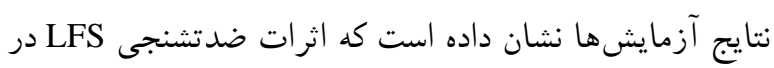

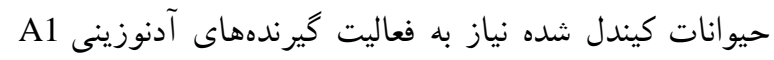

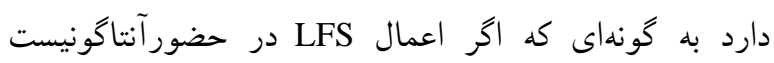
اختصاصى اين خيرنده صورت بخيرد، اثرى بر تنشنج نخواعد أند 
تشنجى LFS اعمال شود، تحر يك يذيرى نورونى كاهش مى يابد.

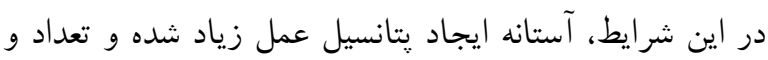

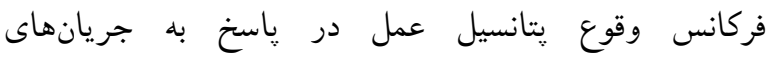

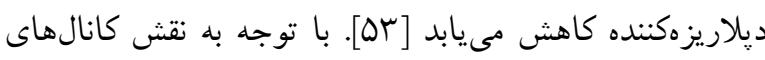

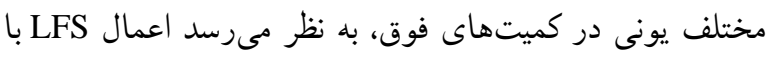

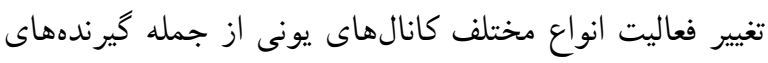

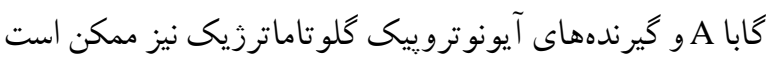
اثرات ضد تشنجى خود را ايجاد نمايد.

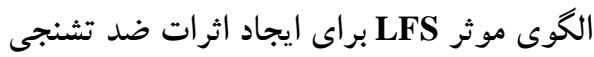

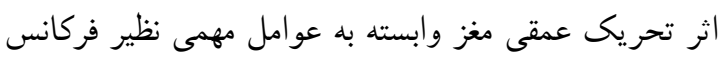

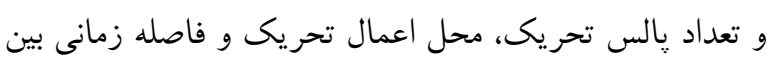

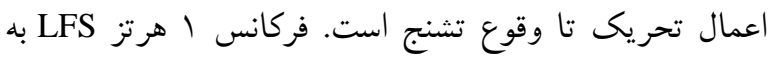

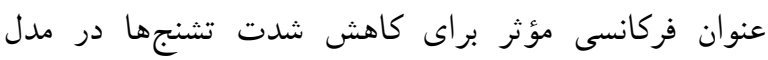

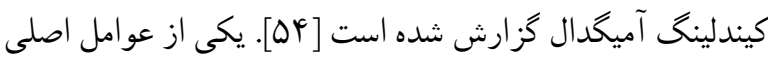
در اثربخشى LFS، محل تحريك است. اعمال تحريكات

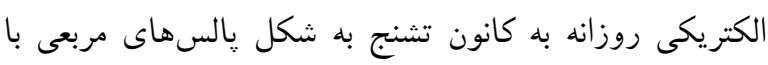

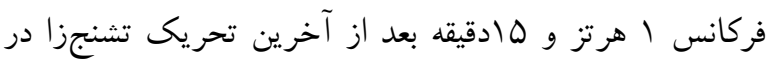

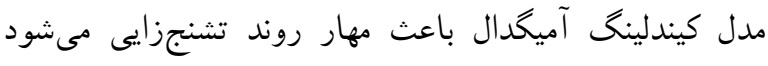

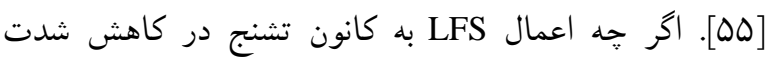

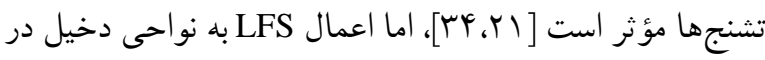

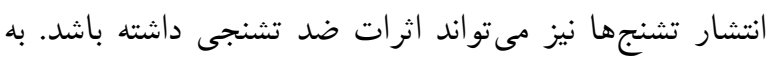

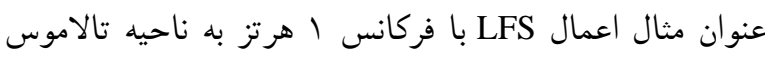

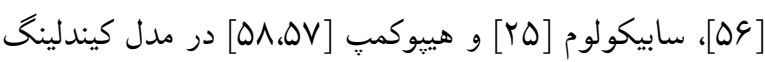

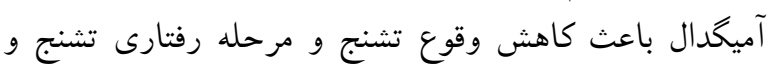

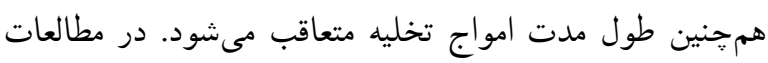

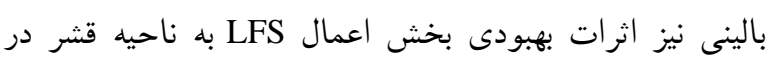

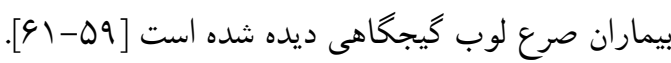

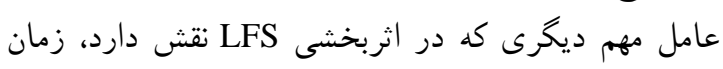

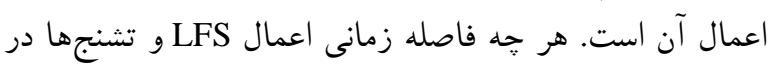

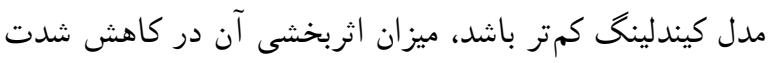

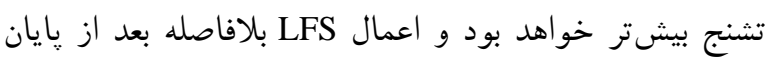
تشنج باعث كاهش دفعات وقوع تشنج، كاهش مرحله رفتار

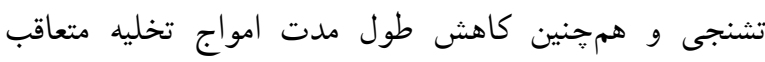

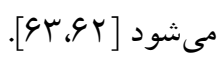

قربانى و همكاران مشاهده كر دند كه اثربخشى LFS به به شدت،

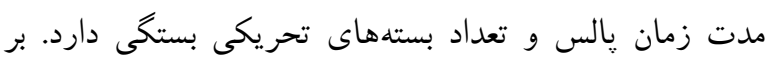

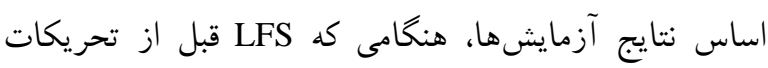

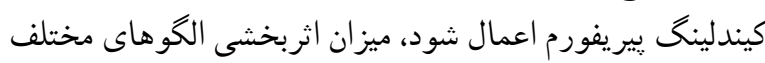

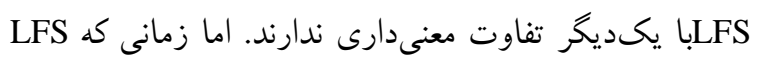

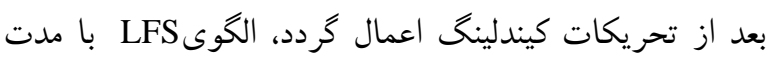
زمان بالس / / • و يا ا ميلىثانيه و شدتى برابر با آستانه امواج
ماثر LFS بر جريانهاى سينايسى در حيوانات تشنجى:

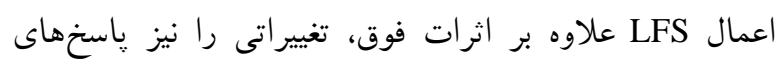
سينايسى از طريق اثر بر جريانهاى مهارى و تحريكى ايجاد

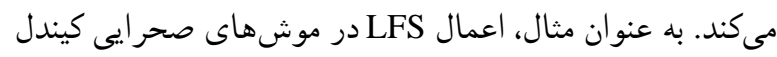

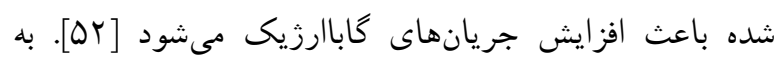

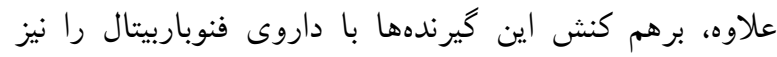

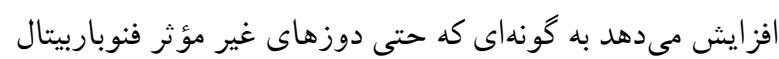

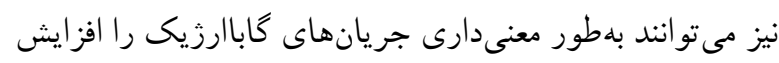

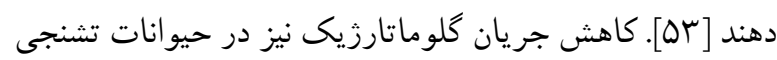

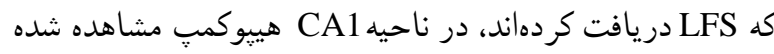

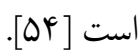

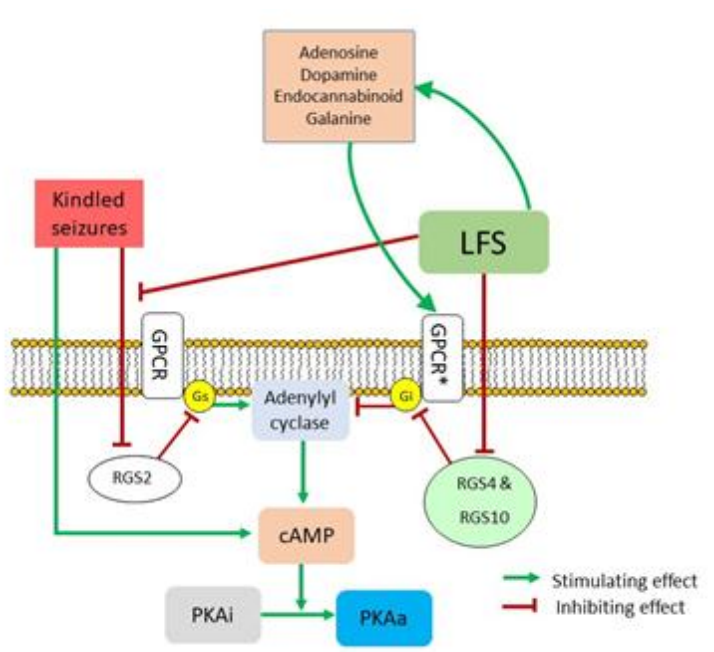

شكل ا. يك مكانيسم احتمالى در ايجاد اثرات ضدتشنجى LFS. تشنج با

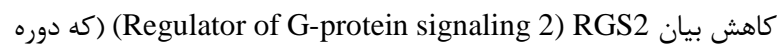

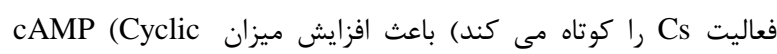
adenosine monophosphate) جلوى اثر كاهنده تشنج بر RGS2, إ مى كيرد و همزمان با كاهش بيان RGS10 , RGS4 (Regulator of G-protein signaling 4) I, Gi كه دوره فعاليت (Regulator of G-protein signaling 10) كاهش مى دهند)، باعث تغيير شرايط به نفع عملكرد Gi شده و در نتيجه (كان

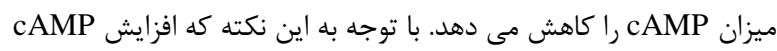

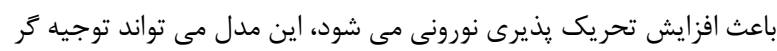
اثر ضدتشنجى LFS باشد. GPCR : G protein-coupled receptor GPCR*

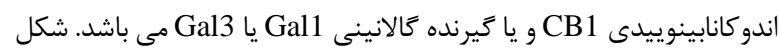
بر اساس منبع •له تنظيم شده است.

اعمال LFS در حيوانات كيندل شده، تحريكيذيرى نورونى

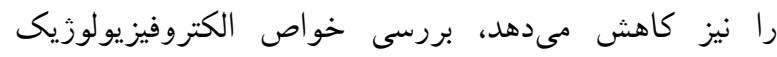

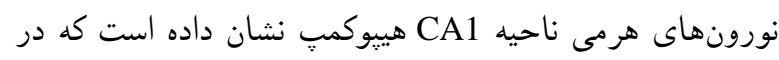

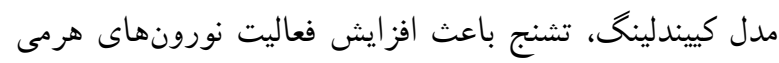

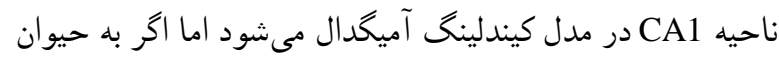


يافت شود، از جمله دستيابى به الخوى بهينه LFS، مشخص نمودن بهترين محل براى اعمال LFS كه بسته به كانون تشنج

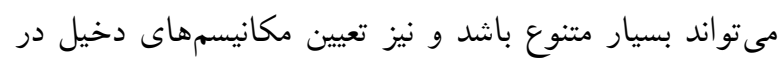
ايجاد اثرات ضد تشنجى LFS كه مورد آخر به ويزه در تعيين

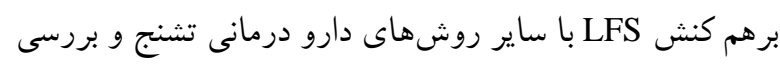

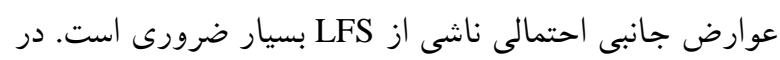

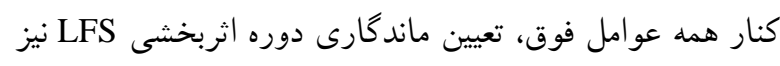

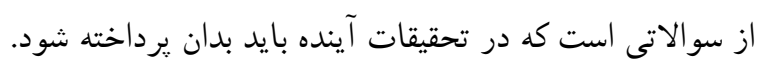

\section{تشكر و قدردانى}

اين كار با حمايت مؤسسه ملى توسعه تحقيقات علوم يزشكى فيكى

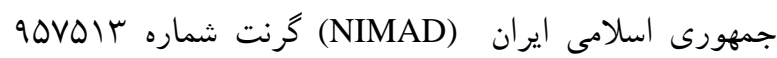

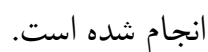

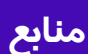

[1] Bell GS, Sander JW. The epidemiology of epilepsy: the size of the problem. Seizure 2001; 10: 306-314.

[2] Banerjee PN, Filippi D, Allen Hauser W. The descriptive epidemiology of epilepsy-a review. Epilepsy Res 2009; 85: 31-45.

[3] Kinton L, Duncan JS. Frequency, causes, and consequences of burns in patients with epilepsy. J Neurol Neurosurg Psychiatry 1998; 65: 404-405.

[4] Theodore WH. Brain stimulation for epilepsy. Nat Clin Pract Neurol 2005; 1: 64-65.

[5] Wiebe S, Blume WT, Girvin JP, Eliasziw M. Effectiveness, efficiency of surgery for temporal lobe epilepsy study G. A randomized, controlled trial of surgery for temporal-lobe epilepsy. $\mathrm{N}$ Engl J Med 2001; 345: 311-318.

[6] Gross RE. Deep brain stimulation in the treatment of neurological and psychiatric disease. Expert Rev Neurother 2004; 4: 465-478.

[7] Cooper IS, Amin I, Gilman S. The effect of chronic cerebellar stimulation upon epilepsy in man. Trans Am Neurol Assoc 1973; 98 : 192-196.

[8] Cooper IS, Upton AR. Therapeutic implications of modulation of metabolism and functional activity of cerebral cortex by chronic stimulation of cerebellum and thalamus. Biol Psychiatry 1985; 20: 811-813.

[9] Delgado JM, Hamlin H, Chapman WP. Technique of intracranial electrode implacement for recording and stimulation and its possible therapeutic value in psychotic patients. Confin Neurol 1952; 12: 315-319.

[10] Heath RG. Electrical self-stimulation of the brain in man. Am J Psychiatry 1963; 120: 571-577.

[11] Cooper IS, Upton AR, Amin I. Reversibility of chronic neurologic deficits. Some effects of electrical stimulation of the thalamus and internal capsule in man. Appl Neurophysiol 1980; 43: 244-258.

[12] Upton AR, Cooper IS, Springman M, Amin I. Suppression of seizures and psychosis of limbic system origin by chronic stimulation of anterior nucleus of the thalamus. Int J Neurol 1985; 19-20: 223-230.

[13] Feddersen B, Vercueil L, Noachtar S, David O, Depaulis A, Deransart C. Controlling seizures is not controlling epilepsy: a parametric study of deep brain stimulation for epilepsy. Neurobiol Dis 2007; 27: 292-300.

[14] Lado FA. Chronic bilateral stimulation of the anterior thalamus of kainate-treated rats increases seizure frequency. Epilepsia 2006; 47: 27-32.

[15] Grill WM, Snyder AN, Miocinovic S. Deep brain stimulation creates an informational lesion of the stimulated nucleus. Neuroreport 2004; 15: 1137-1140.

[16] Burbaud P, Vital A, Rougier A, Bouillot S, Guehl D, Cuny E, Ferrer X, Lagueny A, Bioulac B. Minimal tissue damage after
تخيله متعاقب به طور معنىدارى باعث كاهش مدت زمان مرحله

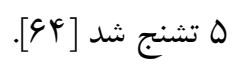

مطالعات نشان دادهاند كه تعداد پالسهاى LFS نيز برای براى

اثربخشى آن بر تشنج مهم است. شهيرى و همكاران در سال

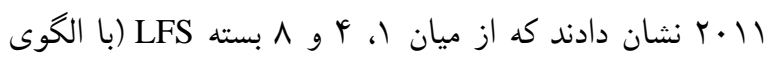

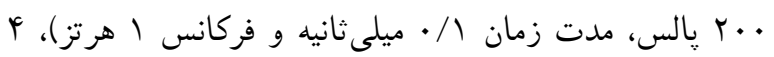
بسته بيشترين اثر ضد تشنجى را در مدل كيندلينگ مسير

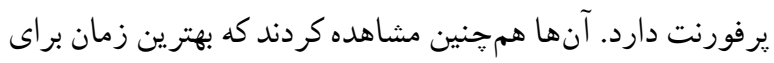
اعمال LFS در حيوانات كيندل شده .ب ثانيه يس از از اتمام

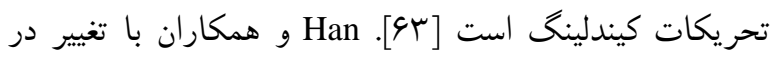

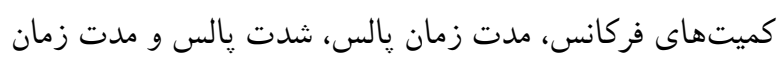

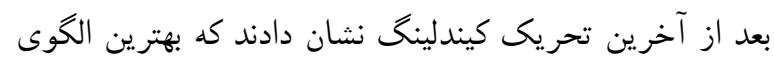

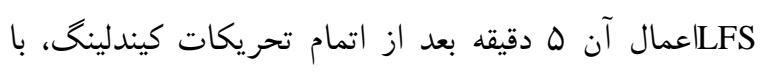

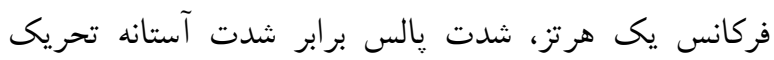
كيندلينخ و مدت زمان ا ميلى ثانيه است [OF] در خصوص مدت دوام اثرات ضدتشنجى LFS نيز نشان داده

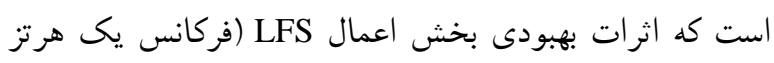

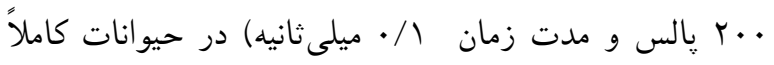
كيندل تا يك هفته بعد از اتمام تحريكات كيندلينخ ادامه دارد

على رغم مطالعات زيادى كه در اين رابطه صورت گر فته، با

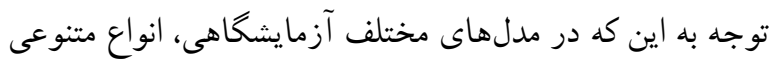

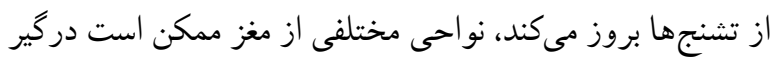

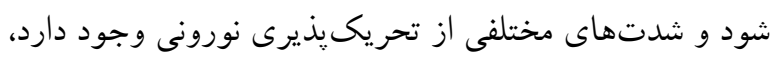

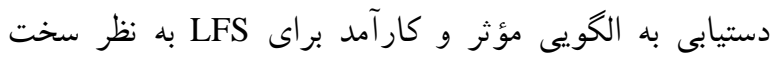

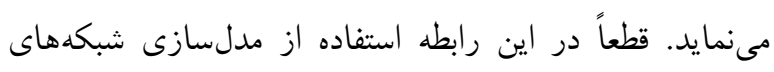

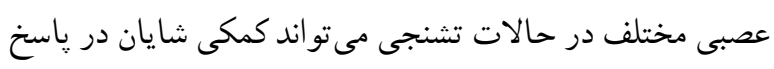
دادن به اين سوال اساسى نمايد. هر جند، در قدم بعد، تعميم اين الخوها به تشنجهاى رخ داده شده در انسان نيز نيازمند تحقيقات

$$
\text { و بررسىهاى بسيار دقيق و علمى مىباشد. }
$$

\section{بحثث و تتيجه تيرى}

اثرات ضدتشنجى LFS در مطالعات بالينى و آزمايشخاهى

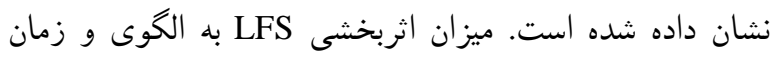

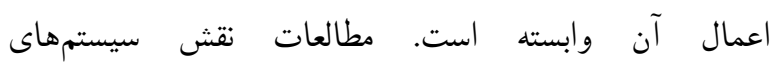

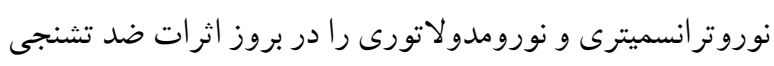

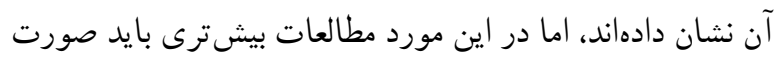

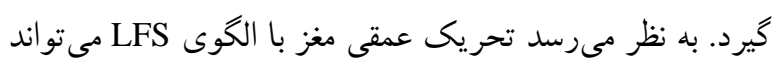

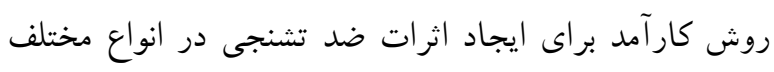

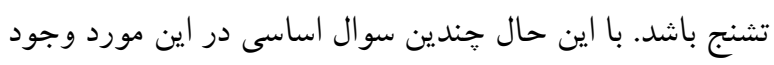

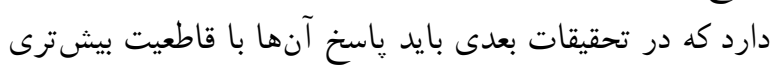


[39] Derkach V, Barria A, Soderling TR. Ca2+/calmodulinkinase II enhances channel conductance of alpha-amino-3-hydroxy5-methyl-4-isoxazolepropionate type glutamate receptors. Proc Natl Acad Sci U S A 1999; 96: 3269-3274.

[40] Beattie EC, Carroll RC, Yu X, Morishita W, Yasuda H, von Zastrow M, Malenka RC. Regulation of AMPA receptor endocytosis by a signaling mechanism shared with LTD. Nat Neurosci 2000; 3 : 1291-1300.

[41] Staubli U, Chun D. Proactive and retrograde effects on LTP produced by theta pulse stimulation: mechanisms and characteristics of LTP reversal in vitro. Learn Mem 1996; 3: 96-105.

[42] Delgado JY, O'Dell T J. Long-term potentiation persists in an occult state following mGluR-dependent depotentiation. Neuropharmacology 2005; 48: 936-948.

[43] Latif-Hernandez A, Faldini E, Ahmed T, Balschun D. Separate Ionotropic and Metabotropic Glutamate Receptor Functions in Depotentiation vs. LTP: A Distinct Role for Group1 mGluR Subtypes and NMDARs. Front Cell Neurosci 2016; 10: 252.

[44] Reyes-Harde M, Stanton PK. Postsynaptic phospholipase C activity is required for the induction of homosynaptic long-term depression in rat hippocampus. Neurosci Lett 1998; 252: 155-158.

[45] Luscher C, Huber KM. Group 1 mGluR-dependent synaptic long-term depression: mechanisms and implications for circuitry and disease. Neuron 2010; 65: 445-459.

[46] Fujii S. ATP- and adenosine-mediated signaling in the central nervous system: the role of extracellular ATP in hippocampal long-term potentiation. J Pharmacol Sci 2004; 94: 103-106.

[47] Zhu PJ. Endocannabinoid signaling and synaptic plasticity in the brain. Crit Rev Neurobiol 2006; 18: 113-124.

[48] Mardani P, Oryan S, Sarihi A, Alaei E, Komaki A, Mirnajafi-Zadeh J. Endocannabinoid CB1 receptors are involved in antiepileptogenic effect of low frequency electrical stimulation during perforant path kindling in rats. Epilepsy Res 2018; 144: 71 81 .

[49] Sadegh M, Mirnajafi-Zadeh J, Javan M, Fathollahi Y, Mohammad-Zadeh M, Jahanshahi A, Noorbakhsh SM. The role of galanin receptors in anticonvulsant effects of low-frequency stimulation in perforant path-kindled rats. Neuroscience 2007; 150 396-403.

[50] Namvar S, Mirnajafi-Zadeh J, Fathollahi Y, Zeraati M. The role of piriform cortex adenosine A1 receptors on hippocampal kindling. Can J Neurol Sci 2008; 35: 226-231.

[51] Mardani P, Oryan S, Sarihi A, Komaki A, Shojaei A, Dehghan S, Mirnajafi-Zadeh J. ERK activation is required for the antiepileptogenic effect of low frequency electrical stimulation in kindled rats. Brain Res Bull 2018; 140: 132-139.

[52] Asgari A, Semnanian S, Atapour N, Shojaei A, MoradiChameh H, Ghafouri S, et al. Low-frequency electrical stimulation enhances the effectiveness of phenobarbital on GABAergic currents in hippocampal slices of kindled rats. Neuroscience 2016; 330: 2638 .

[53] Shojaei A, Semnanian S, Janahmadi M, Moradi-Chameh H, Firoozabadi SM, Mirnajafi-Zadeh J. Repeated transcranial magnetic stimulation prevents kindling-induced changes in electrophysiological properties of rat hippocampal CA1 pyramidal neurons. Neuroscience 2014; 280: 181-192.

[54] Han Y, Wang Y. Therapeutic effect of low frequency electric stimulation on the epileptogenic focus in amygdale-kindled rats. Int J Clin Exp Med 2014; 7: 4091-4098.

[55] Yang LX, Jin CL, Zhu-Ge ZB, Wang S, Wei EQ, Bruce IC, Chen Z. Unilateral low-frequency stimulation of central piriform cortex delays seizure development induced by amygdaloid kindling in rats. Neuroscience 2006; 138: 1089-1096.

[56] Zhong XL, Lv KR, Zhang Q, Yu JT, Xing YY, Wang ND, Tan L. Low-frequency stimulation of bilateral anterior nucleus of thalamus inhibits amygdale-kindled seizures in rats. Brain Res Bull 2011; 86: 422-427.

[57] Wang L, Shi J, Wu G, Zhou F, Hong Z. Hippocampal lowfrequency stimulation increased SV2A expression and inhibited the seizure degree in pharmacoresistant amygdala-kindling epileptic rats. Epilepsy Res 2014; 108: 1483-1491.

[58] Zhang SH, Sun HL, Fang Q, Zhong K, Wu DC, Wang S, Chen Z. Low-frequency stimulation of the hippocampal CA3 subfield is anti-epileptogenic and anti-ictogenic in rat amygdaloid kindling model of epilepsy. Neurosci Lett 2009; 455: 51-55.

[59] Schrader LM, Stern JM, Wilson CL, Fields TA, Salamon N, Nuwer MR, et al. Low frequency electrical stimulation through subdural electrodes in a case of refractory status epilepticus. Clin Neurophysiol 2006; 117: 781-788. stimulation of the motor thalamus in a case of chorea-acanthocytosis. Neurology 2002; 59: 1982-1984.

[17] Manahan-Vaughan D. Long-term depression in freely moving rats is dependent upon strain variation, induction protoco and behavioral state. Cereb Cortex 2000; 10: 482-487.

[18] Li Y, Mogul DJ. Electrical control of epileptic seizures. J Clin Neurophysiol 2007; 24: 197-204.

[19] Cordeiro JG, Somerlik KH, Cordeiro KK, Aertsen A, Araujo JC, Schulze-Bonhage A. Modulation of excitability by continuous low- and high-frequency stimulation in fully hippocampal kindled rats. Epilepsy Res 2013; 107: 224-230.

[20] Gaito J, Nobrega JN, Gaito ST. Interference effect of $3 \mathrm{~Hz}$ brain stimulation on kindling behavior induced by $60 \mathrm{~Hz}$ stimulation. Epilepsia 1980; 21: 73-84.

[21] Goodman JH, Berger RE, Tcheng TK. Preemptive lowfrequency stimulation decreases the incidence of amygdala-kindled seizures. Epilepsia 2005; 46: 1-7.

[22] Kinoshita M, Ikeda A, Matsumoto R, Begum T, Usui K, Yamamoto J, et al. Electric stimulation on human cortex suppresses fast cortical activity and epileptic spikes. Epilepsia 2004; 45: 787-91.

[23] Lim SN, Lee CY, Lee ST, Tu PH, Chang BL, Lee CH, et al Low and high frequency hippocampal stimulation for drug-resistant mesial temporal lobe epilepsy. Neuromodulation 2016; 19: 365-372.

[24] Bragin A, Wilson CL, Engel J, Jr. Rate of interictal events and spontaneous seizures in epileptic rats after electrical stimulation of hippocampus and its afferents. Epilepsia 2002; 43: 81-85.

[25] Zhong K, Wu DC, Jin MM, Xu ZH, Wang Y, Hou WW, et al. Wide therapeutic time-window of low-frequency stimulation at the subiculum for temporal lobe epilepsy treatment in rats. Neurobio Dis 2012; 48: 20-26.

[26] Kanner AM. Deep brain stimulation for intractable epilepsy: which target and for which seizures? Epilepsy Curr 2004; 4: 231-232.

[27] Kile KB, Tian N, Durand DM. Low frequency stimulation decreases seizure activity in a mutation model of epilepsy. Epilepsia 2010; 51: 1745-1753

[28] Weiss SR, Li XL, Rosen JB, Li H, Heynen T, Post RM Quenching: inhibition of development and expression of amygdala kindled seizures with low frequency stimulation. Neuroreport 1995 6: 2171-2176.

[29] Staubli U, Lynch G. Stable depression of potentiated synaptic responses in the hippocampus with $1-5 \mathrm{~Hz}$ stimulation. Brain Res 1990; 513: 113-118.

[30] Barrionuevo G, Schottler F, Lynch G. The effects of repetitive low frequency stimulation on control and "potentiated" synaptic responses in the hippocampus. Life Sci 1980; 27: 2385 2391.

[31] Fujii S, Saito K, Miyakawa H, Ito K, Kato H. Reversal of long-term potentiation (depotentiation) induced by tetanus stimulation of the input to CA1 neurons of guinea pig hippocampal slices. Brain Res 1991; 555: 112-122.

[32] Bashir ZI, Collingridge GL. An investigation of depotentiation of long-term potentiation in the CA1 region of the hippocampus. Exp Brain Res 1994; 100: 437-443.

[33] Adamec RE. Evidence that limbic neural plasticity in the right hemisphere mediates partial kindling induced lasting increases in anxiety-like behavior: effects of low frequency stimulation (quenching?) on long term potentiation of amygdala efferents and behavior following kindling. Brain Res 1999; 839: 133-152.

[34] Mohammad-Zadeh M, Mirnajafi-Zadeh J, Fathollahi Y, Javan M, Jahanshahi A, Noorbakhsh SM, Motamedi F. The role of adenosine $\mathrm{A}(1)$ receptors in mediating the inhibitory effects of low frequency stimulation of perforant path on kindling acquisition in rats. Neuroscience 2009; 158: 1632-1643.

[35] Jahanshahi A, Mirnajafi-Zadeh J, Javan M, MohammadZadeh M, Rohani R. The antiepileptogenic effect of electrical stimulation at different low frequencies is accompanied with change in adenosine receptors gene expression in rats. Epilepsia 2009; 50: 1768-1779

[36] Kang-Park $\mathrm{MH}$, Sarda MA, Jones $\mathrm{KH}$, Moore SD, Shenolikar S, Clark S, Wilson WA. Protein phosphatases mediate depotentiation induced by high-intensity theta-burst stimulation. J Neurophysiol 2003; 89: 684-690.

[37] Lee HK, Barbarosie M, Kameyama K, Bear MF, Huganir RL. Regulation of distinct AMPA receptor phosphorylation sites during bidirectional synaptic plasticity. Nature 2000; 405: 955-959.

[38] Shenolikar S, Nairn AC. Protein phosphatases: recent progress. Adv Second Messenger Phosphoprotein Res 1991; 23: 1121. 
[69] McLachlan RS, Pigott S, Tellez-Zenteno JF, Wiebe S, Parrent A. Bilateral hippocampal stimulation for intractable temporal lobe epilepsy: impact on seizures and memory. Epilepsia 2010; 51: 304-307.

[70] Morrell MJ, Group RNSSiES. Responsive cortical stimulation for the treatment of medically intractable partial epilepsy. Neurology 2011; 77: 1295-1304.

[71] Cukiert A, Burattini JA, Cukiert CM, Argentoni-Baldochi M, Baise-Zung C, Forster CR, Mello VA. Centro-median stimulation yields additional seizure frequency and attention improvement in patients previously submitted to callosotomy. Seizure 2009; 18 : 588592.

[72] Valentin A, Garcia Navarrete E, Chelvarajah R, Torres C, Navas M, Vico L, et al. Deep brain stimulation of the centromedian thalamic nucleus for the treatment of generalized and frontal epilepsies. Epilepsia 2013; 54: 1823-1833.

[73] Kowski AB, Voges J, Heinze HJ, Oltmanns F, Holtkamp M, Schmitt FC. Nucleus accumbens stimulation in partial epilepsy--a randomized controlled case series. Epilepsia 2015; 56: e78-82.

[74] Chkhenkeli SA, Sramka M, Lortkipanidze GS, Rakviashvili TN, Bregvadze E, Magalashvili GE, et al. Electrophysiological effects and clinical results of direct brain stimulation for intractable epilepsy. Clin Neurol Neurosurg 2004; 106: 318-329.

[75] Velasco F, Carrillo-Ruiz JD, Brito F, Velasco M, Velasco AL, Marquez I, Davis R. Double-blind, randomized controlled pilot study of bilateral cerebellar stimulation for treatment of intractable motor seizures. Epilepsia 2005; 46: 1071-1081.
[60] Yamamoto J, Ikeda A, Kinoshita M, Matsumoto R, Satow $\mathrm{T}$, Takeshita K, et al. Low-frequency electric cortical stimulation decreases interictal and ictal activity in human epilepsy. Seizure 2006; 15: 520-527.

[61] Kinoshita M, Ikeda A, Matsuhashi M, Matsumoto R, Hitomi $\mathrm{T}$, Begum T, et al. Electric cortical stimulation suppresses epileptic and background activities in neocortical epilepsy and mesial temporal lobe epilepsy. Clin Neurophysiol 2005; 116: 1291-1299.

[62] Wu DC, Xu ZH, Wang S, Fang Q, Hu DQ, Li Q, et al. Timedependent effect of low-frequency stimulation on amygdaloidkindling seizures in rats. Neurobiol Dis 2008; 31: 74-79.

[63] Shahpari M, Mirnajafi-Zadeh J, Firoozabadi SM, Yadollahpour A. Effect of low-frequency electrical stimulation parameters on its anticonvulsant action during rapid perforant path kindling in rat. Epilepsy Res 2012; 99: 69-77.

[64] Ghorbani P, Mohammad-Zadeh M, Mirnajafi-Zadeh J, Fathollahi Y. Effect of different patterns of low-frequency stimulation on piriform cortex kindled seizures. Neurosci Lett 2007; 425: $162-166$

[65] Esmaeilpour K, Sheibani V, Shabani M, Mirnajafi-Zadeh J. Low frequency electrical stimulation has time dependent improving effect on kindling-induced impairment in long-term potentiation in rats. Brain Res 2017; 1668: 20-27.

[66] Fisher R, Salanova V, Witt T, Worth R, Henry T, Gross R, et al. Electrical stimulation of the anterior nucleus of thalamus for treatment of refractory epilepsy. Epilepsia 2010; 51: 899-908.

[67] Van Gompel JJ, Klassen BT, Worrell GA, Lee KH, Shin C, Zhao CZ, et al. Anterior nuclear deep brain stimulation guided by concordant hippocampal recording. Neurosurg Focus 2015; 38: E9.

[68] Valentin A, Selway RP, Amarouche M, Mundil N, Ughratdar I, Ayoubian L, et al. Intracranial stimulation for children with epilepsy. Eur J Paediatr Neurol 2017; 21: 223-231. 


\title{
Review Article \\ Control of epileptic seizures by electrical low frequency deep brain stimulation: A review of probable mechanisms
}

\author{
Meysam Zare (M.Sc) ${ }^{1}$, Amir Shojaei (Ph.D) ${ }^{2,1}$, Seyyed Javad Mirnajarizadeh (Ph.D) ${ }^{* 1}$ \\ 1- Dept. of Physiology, Faculty of Medical Sciences, Tarbiat Modares University, Tehran, Iran \\ 2- Dept. of Brain and Cognitive Sciences, Cell Science Research Center, Royan Institute for Stem Cell Biology and Technology, ACECR, Tehran, \\ Iran
}

* Corresponding author. +98 21-82883865 mirnajaf@modares.ac.ir

Received: 25 Jan 2019; Accepted: 25 May 2019

Epilepsy is the most common neurological disease with no definitive method in treatment. Notably, the main way to treat and control epileptic seizures is drug therapy. However, about 20-30\% of patients with epilepsy are drug resistant and require other therapeutic manners. Deep brain stimulation is a new therapeutic strategy for these patients. Conspicuously, there are no clear answers for basic questions such as which brain area is a suitable target for stimulation, which pattern of stimulation exerts the best therapeutic effects and what is the probable mechanism of anticonvulsant effect of deep brain stimulation? Using laboratory models of epilepsy and seizure, it has been shown that low frequency electrical stimulation (LFS) is an effective pattern of deep brain stimulation to reduce the seizure severity. The mechanisms involved in LFS anticonvulsant effects are not completely determined. In this article, we reviewed the previous studies on the anticonvulsant effects of LFS and the possible mechanisms involved in it, as well as LFS-induced changes in the neuronal activities.

Keywords: Epilepsy; Deep brain stimulation; Low frequency stimulation; Anticonvulsant effect. 